Annales Geophysicae (2003) 21: 1039-1045 (C) European Geosciences Union 2003

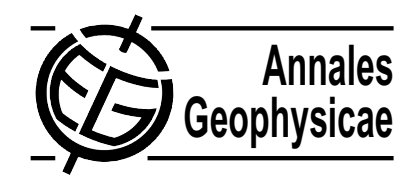

\title{
The intermediate layers and associated tidal motions observed by a digisonde in the equatorial anomaly region
}

\author{
C.-C. Lee ${ }^{1}$, J.-Y. Liu ${ }^{1,2}$, C.-J. Pan ${ }^{1}$, and H.-H. Hsu ${ }^{1}$ \\ ${ }^{1}$ Institute of Space Science, National Central University, NO. 300, Jung-da Rd., Chung-Li 320, Taiwan \\ ${ }^{2}$ Center for Space and Remote Sensing Research, National Central University, NO. 300, Jung-da Rd. Chung-Li 320, Taiwan
}

Received: 12 April 2002 - Revised: 25 September 2002 - Accepted: 18 October 2002

\begin{abstract}
This investigation presents an initial attempt to analyze a full year of daily ionosonde observations relevant to the determination of plasma densities, tidal structures, and ion transports in the equatorial anomaly region of the lower ionosphere. Particular focus is on the intermediate layers, their seasonal and diurnal variations, and cause-effect relationships. The ionogram database was recorded using a digisonde portable sounder (DPS) at National Central University (NCU, $\left.24^{\circ} 58^{\prime} \mathrm{N}, 121^{\circ} 11^{\prime} \mathrm{E}\right)$ during 1996 . Statistical results indicate that the intermediate layers appear primarily during the daytime of the spring/winter months. The monthly median height characteristics reveal that the layers descend from high to low altitudes and different tidal motions control the layers in different months. Generally, the semi-diurnal and quarter-diurnal tides, which cause ionization convergence, are mainly in the spring/winter and summer/autumn months, respectively. Variations in the electron densities of the layers also indicate that the density increases could result from a great number of molecular and metallic ions. Furthermore, a novel approach to ionogram presentation is introduced to investigate the intermediate layers. This approach allows the DPS to characterize the detailed daily information of the intermediate layers.
\end{abstract}

Key words. Ionosphere (equatorial ionosphere; ionosphereatmosphere interactions; ionospheric irregularities)

\section{Introduction}

At middle and low latitudes, the major ionospheric regions are generally designated as D, E, F1, and F2, where the maximum electron concentrations, respectively, follow the order $10^{9}, 10^{11}, 10^{11}-10^{12}$, and $10^{12} \mathrm{el} / \mathrm{m}^{3}$ under normal daytime conditions (e.g. Kelley, 1989). Unlike the normal layers, the intermediate layers form at the F-region bottomside and then gradually descend through the E-F valley region of the ionosphere (e.g. Mathews, 1998). Thin ( $\sim 5 \mathrm{~km}$

Correspondence to: C.-C. Lee (cclee@ jupiter.ss.ncu.edu.tw) vertical thickness) plasma layers with densities of $10^{11} 10^{12}$ and $10^{9}-10^{10} \mathrm{el} / \mathrm{m}^{3}$ form in the daytime and nighttime, respectively (Wilkinson et al., 1992; Mathews et al., 1993; Szuszczewicz et al., 1995; Earle et al., 2000).

The intermediate layers have been studied using incoherent scatter radar (ISR) for nearly three decades. Shen et al. (1976) demonstrated a series of ISR density profiles over the Arecibo Observatory $\left(\mathrm{AO}, 18.35^{\circ} \mathrm{N}, 66.75^{\circ} \mathrm{W}\right)$ that showed the layer periods to be several hours. Mathews and Bekeny (1979) investigated the wind system comprising of diurnal and semi-diurnal tides using the AO ISR. Also, Morton et al. (1993) and Mathews et al. (1993) confirmed the regular quarter-diurnal periodicity of the layers during the Arecibo Initiative in Dynamics of the Atmosphere (AIDA) campaign. Additionally, ionosonde has also been used to investigate the layers. MacDougall (1978) studied the intermediate layers from ionograms and noted that their periodicities were related to the semi-diurnal tidal oscillations. Moreover, Rodger et al. (1981) showed the characteristics of the nocturnal intermediate layers based on ionograms from South Georgia ( $54.8^{\circ} \mathrm{S}, 323.5^{\circ}$ E). Finally, Szuszczewicz et al. (1995) exploited the SUNDIAL data and TIGCM model to investigate the intermediate layers and designed a variety of tidal controls.

From the early studies (Fujitaka and Tohmatsu, 1973; MacDougall, 1978; Mathews et al., 1993), the intermediate layers result primarily from wind shears connected with the motions of several tide modes. In the upper E-region, the meridional neutral wind is found to respond mainly to the upward and downward ion drifts that induce layer formation (e.g. Whitehead, 1989; Mathews, 1998). When wind shear is null, the ion convergence region (Whitehead, 1961; Axford, 1963) descends, as does the intermediate layer.

Although the intermediate layers have been extensively studied, no studies have focused on the long-period all-day data in the equatorial anomaly region. This work explores the essential features of the intermediate layers. According, a Digisonde Portable Sounder (DPS) at the National Central University (NCU-DPS) is utilized for long-term ionospheric 


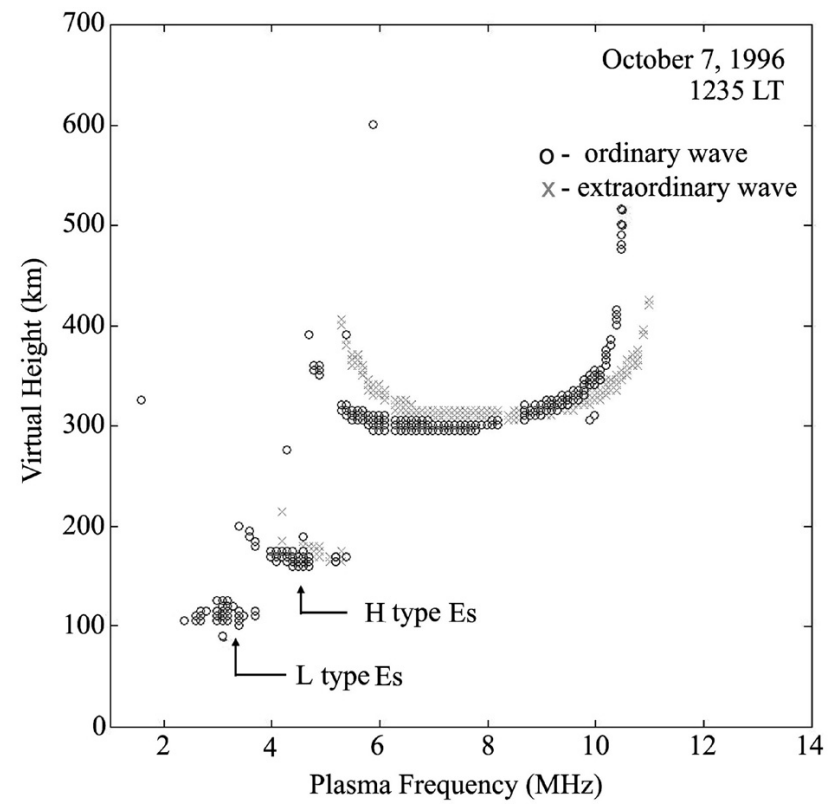

Fig. 1. Sample ionogram illustrating the sporadic-E (L type) and intermediate layer ( $\mathrm{H}$ type) observation as seen by the digisonde system. The circle represents the ordinary wave, while the cross is the extraordinary wave.

observation during 1996. The statistical results are then applied to examine the characteristics and periodicities of the intermediate layers.

\section{Observations and database}

DPS is an advanced digital ionosonde, which derives realtime ionospheric parameters (Reinisch, 1995, 1996). Since 1995, NCU-DPS has been employed to monitor the ionospheric equatorial anomaly in the western Pacific region. A peak transmitting power of $500 \mathrm{~W}$ is applied in the ionogram mode with a $5 \mathrm{~km}$ resolution range. Meanwhile, the sounding frequency varies from 1.0 to $16.0 \mathrm{MHz}$, with a frequency increment of $0.1 \mathrm{MHz}$. Data acquisition allows digitized signals with separate echo polarizations (O- and $\mathrm{X}$ - modes) to be used easily to investigate the ionosphere (Reinisch, 1996). During 1996, 317 all-day ionograms with a time resolution of $15 \mathrm{~min}$ were recorded by the NCU-DPS, with recordings being taken throughout the year, except for maintenance periods.

The sporadic-E (Es) layer is classified into one of 11 types in which $\mathrm{H}$ (high), C (cusp), L (low), and F (flat) types are generally observed in middle latitudes. These types of Es appear sometime individually or simultaneously (e.g. Wakai et al., 1987; Davies, 1990). During 1996, in the equatorial anomaly region, the $f o$ Es (maximum frequency of the Eslayer) of $\mathrm{H} / \mathrm{C}$ type Es is usually greater than that of $\mathrm{L}$ type Es during the daytime; then these two types of Es can simultaneously show on observed ionogram (for example, see Fig. 1). However, if the $f o$ Es of $\mathrm{L} / \mathrm{F}$ type Es is greater than that of the

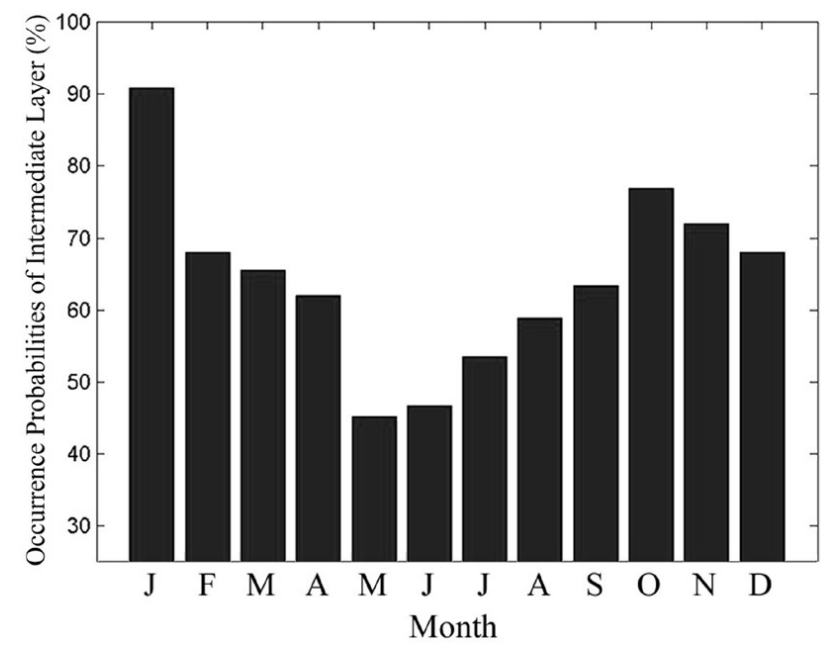

Fig. 2. Monthly variations in occurrence probability of the intermediate layers at the observation site throughout 1996. The highest occurrence probability (90\%) occurs in January, while the lowest value appears in May.

$\mathrm{H} / \mathrm{C}$ type one, the H/C type Es would not appear due to the effect of blanketing Es. During the nighttime, the H/C type Es rarely appears, while the $\mathrm{F}$ type Es mostly occurs.

According the scaling ionogram rule (Wakai et al., 1987), when two types of Es simultaneously appear, the $f o$ Es and $h^{\prime}$ Es (minimum virtual height of the Es layer) are recorded from the type having the highest $f o$ Es. For reserving more complete data, the foEs and $h^{\prime}$ Es of all Es types are recorded concurrently for detailed investigation. In this work, we used only the virtual height ( $h^{\prime}$ Es), because the true height analysis could not analyze such kinds of Es trace (Reinisch et al., 1983; Titheridge, 1985). Notably, the plasma density can be derived from the radio (plasma) frequency (for example, see Davies, 1990).

\section{Results}

\subsection{Seasonal and diurnal variations}

According to Wilkinson et al. (1992) and Szuszczewicz et al. (1995), the $H$ and $C$ type Es are attributed to the intermediate layers. Therefore, this statistical analysis implements only the $\mathrm{H}$ and $\mathrm{C}$ type Es to study the intermediate layers. The seasonal and diurnal variations in the occurrence probabilities of the layer are the percentage of days on which at least one layer is observed daily and every $15 \mathrm{~min}$, respectively. Since ionogram samples exceed 30000 , the results are statistically significant. The monthly median values of $h^{\prime}$ Es and $f o$ Es of these types of Es are utilized to identify the characteristics of the layers.

Figure 2 presents the seasonal variation in the occurrence probabilities of the intermediate layer. Clearly, the layer is most prevalent (90\% of occurrence probability of the layer) in January, namely the winter, while the lowest occurrence 


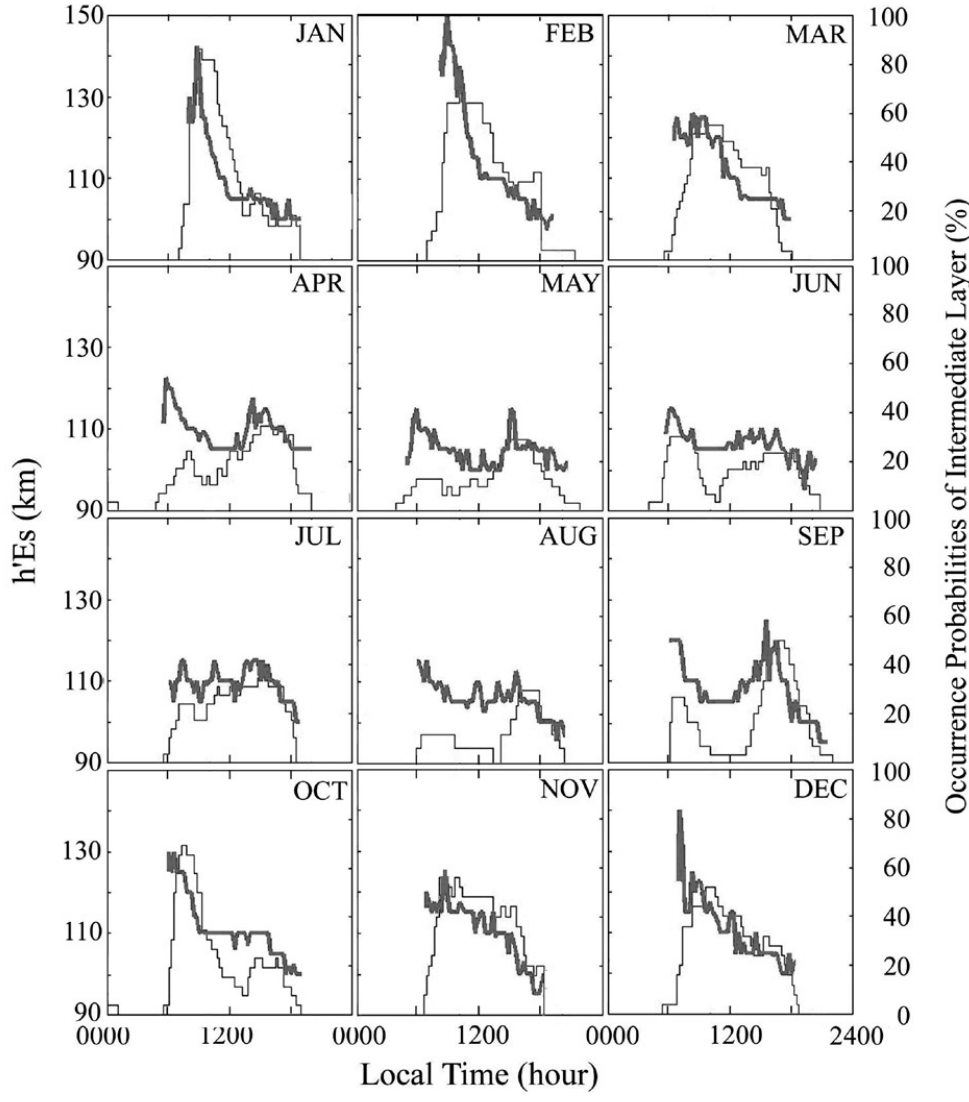

Fig. 3. Median values of the $h^{\prime}$ Es (bold line) of the intermediate layer in January-December, respectively. The histogram in the background is the associated occurrence probability of the intermediate layers. The single peak (> 50\%) of occurrence probability appears in spring and winter, while the double peak $(<50 \%)$ appears in summer and autumn. Additionally, the one descent of the layer occurs in the singlepeak months, while the two descents appear in the double-peak months. probability $(45 \%)$ is in May, namely the summer. Notably, the occurrence probability exceeds $65 \%$ during JanuaryMarch and October-December. In contrast, the occurrence probability is below 65\% during May-September. Generally, the occurrence probability is higher in spring/winter than in summer/autumn.

Figure 3 illustrates the diurnal distributions of the occurrence probability (histogram in background) of the intermediate layers from January to December. During the spring (February and March) and winter (November, December, and January), the occurrence probability shows a single peak during daytime, occurring at around 09:30 local time (LT = UT $+8 \mathrm{~h}$ ). Notice that the percentages of these peaks exceed 50\%. During the other months (except July), double peaks appear in the daytime, but the occurrence probabilities are mostly below 50\%. Specifically, a morning peak occurs at around 08:00 LT, while an afternoon peak occurs at around 16:00-17:00 LT. Overall, the time intervals between the two peaks are approximately $8 \mathrm{~h}$ in April-June and August-October. Notably, the occurrence probability is also less than $50 \%$ and no clear peaks occur in July.

Additionally, Fig. 3 displays the associated monthly median $h^{\prime}$ Es (bold line) of the intermediate layers. In the single-peak months, the layers clearly descend from high $(>130 \mathrm{~km}$ ) to low (about $105 \mathrm{~km}$ ) altitudes during the daytime. The layers generally start to descend at around 06:30 LT, and finish their descent by approximately 18:00 LT.
Notably, the time required to complete the descent is about $12 \mathrm{~h}$. During January-March and November-December, the descent is initially fast, $4-8 \mathrm{~km} / \mathrm{h}$ and later slows to $0.5-1.7 \mathrm{~km} / \mathrm{h}$ below approximately $110 \mathrm{~km}$. However, for the double-peak months (April-June and August-October), both morning and afternoon descent rates are around 2$4 \mathrm{~km} / \mathrm{h}$ during 06:30-12:00 LT and 15:00-21:00 LT. It is noted that the descent periods are approximately $6 \mathrm{~h}$ during these months.

For further study, the monthly median foEs (thin line in Fig. 4) of the intermediate layers are compared with the associated $h^{\prime}$ Es (bold line). Clearly, the maximum $f o$ Es of around $4-6 \mathrm{MHz}$ generally appears at noon. Interestingly, the foEs (plasma density) of the intermediate layer begins to increase when the layer starts to descend during January-March and November-December. The morning descents in April-June and August-October also display a similar phenomenon. In contrast, the density of the layer decreases as the layer descends in the afternoon during these months.

\subsection{Height-Time-Frequency (HTF) plot}

This investigation develops a new approach to view the ionogram data for detailed examination of the intermediate layers. The maximum frequencies associated with the $\mathrm{H}, \mathrm{C}, \mathrm{L}$, and $\mathrm{F}$ type Es at each altitude in a sequence of ionograms are all maintained to create the height-time-frequency (HTF) 


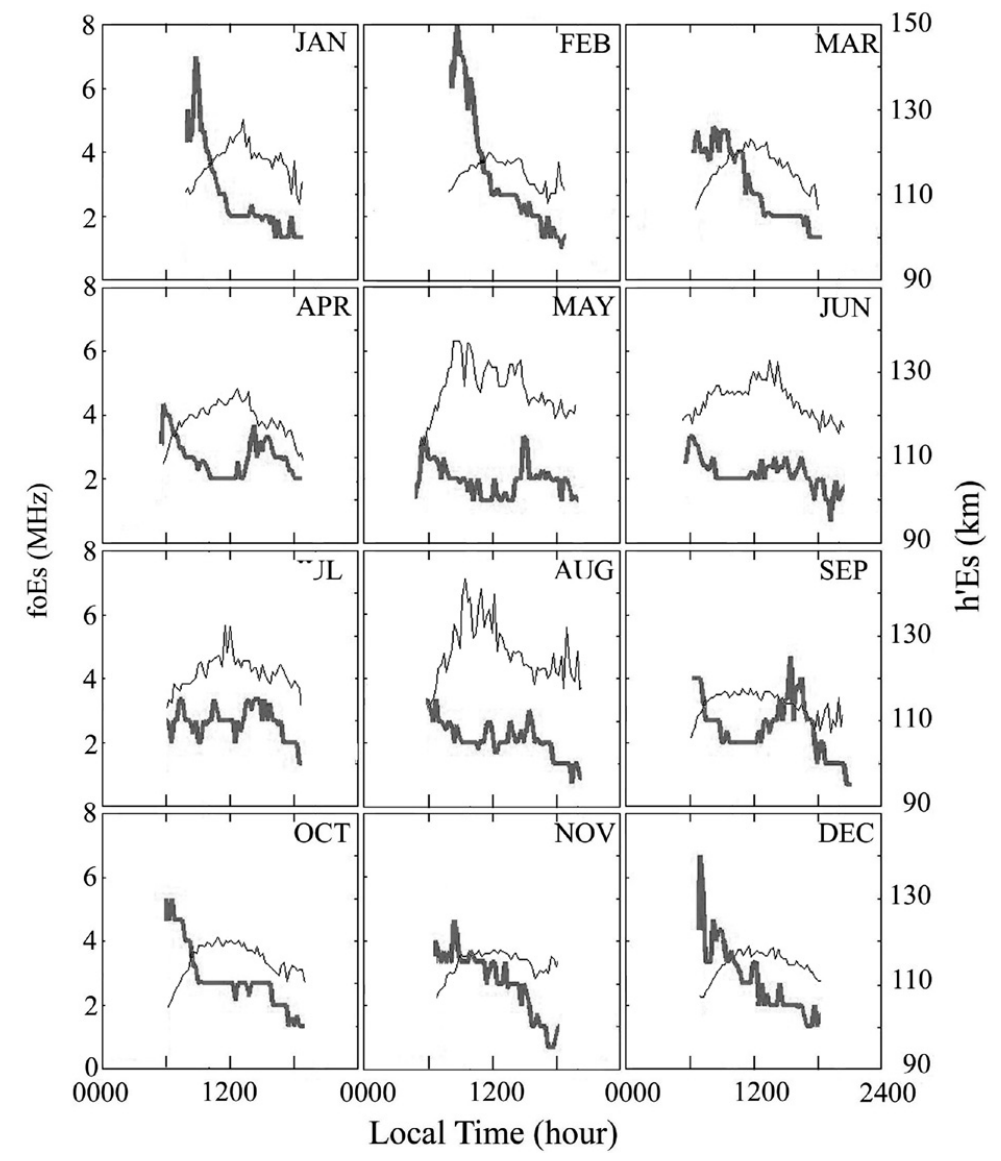

Fig. 4. Median values of the foEs (thin line) of the intermediate layer in January-December, respectively. The bold line represents the $h^{\prime}$ Es associated with the intermediate layers. The descents of the layer in the single-peak months and of the morning layer in the double-peak months are related to the increase of layer frequency (density). plot. Notably, to represent the plasma density, only ordinary waves of returned signals are displayed in the HTF plot. Figure 5 displays the layer variations based on two all-day HTF samples in January and April, respectively. The horizontal axis of the HTF plot represents the local time, the vertical axis is the virtual height, and the colored level indicates the plasma frequency.

Figure 5a presents the HTF plot from the NCU-DPS on 16 January 1996, in which the $\mathrm{H}$ type Es-layer with foEs $2.6 \mathrm{MHz}$ (corresponding to plasma density of $8.3 \times$ $10^{10} \mathrm{el} / \mathrm{m}^{3}$ ) appears and descends from $170 \mathrm{~km}$ altitude after 07:15 LT. The descent is fast initially, $\sim 22 \mathrm{~km} / \mathrm{h}$ and then slows to $\sim 2 \mathrm{~km} / \mathrm{h}$, as the associated plasma density increases once the layer drops below $115 \mathrm{~km}$. Notably, the maximum plasma frequency is $18 \mathrm{MHz}\left(4 \times 10^{12} \mathrm{el} / \mathrm{m}^{3}\right)$ at $12: 40 \mathrm{LT}$. After 17:30 LT, the density of the layer begins to decline, and the layer finally disappears after 19:45 LT.

Figure $5 \mathrm{~b}$ displays the other main event involving the intermediate layers on 12 April 1996. In this case, two distinct descending layers occur during the daytime. The morning layer appears from 06:00 LT $\left(2 \mathrm{MHz}, 4.9 \times 10^{10} \mathrm{el} / \mathrm{m}^{3}\right)$, and begins to descend at a rate of $\sim 10 \mathrm{~km} / \mathrm{h}$. After 08:00 LT, once the layer declines below $110 \mathrm{~km}$, the rate of decline slows and the density increases. The maximum frequency (density) of $11.4 \mathrm{MHz}\left(1.6 \times 10^{12} \mathrm{el} / \mathrm{m}^{3}\right)$ appears at 10:25 LT, and the layer abruptly disappears at 11:30 LT. Similarly, the after- noon one with $4.4 \mathrm{MHz}\left(2.4 \times 10^{11} \mathrm{el} / \mathrm{m}^{3}\right)$ starts to descend at a rate of $\sim 17 \mathrm{~km} / \mathrm{h}$ from 13:15 LT. The plasma frequency of the afternoon layer does not increase significantly during the descent of this layer, and fades out at 19:30 LT.

\section{Discussion}

This work used the $\mathrm{H}$ and $\mathrm{C}$ type Es obtained by the NCUDPS to study the behavior of the intermediate layers in the equatorial anomaly region. Statistical results reveal that the occurrence probabilities and periodicities of the layers vary according to season and local time. Additionally, the descent rates of the layers are derived and displayed. From early works, the redistributing ionization and motions in the intermediate region are influenced mainly by the meridional wind shear and associated tides (Fujitaka and Tohmatsu, 1973; MacDougall, 1978; Whitehead, 1989; Mathews et al., 1993; Mathews, 1998). Consequently, the mechanisms of the layers are applied to explain the observations obtained by NCUDPS.

First, Fig. 2 illustrates that the layer occurs most frequently during the local winter. Rodger et al. (1981) demonstrated a similar phenomenon, finding the layer to be observed most frequently around mid-winter. Furthermore, in a tidal study, Amayenc (1974) found that the amplitude of the semi-diurnal 


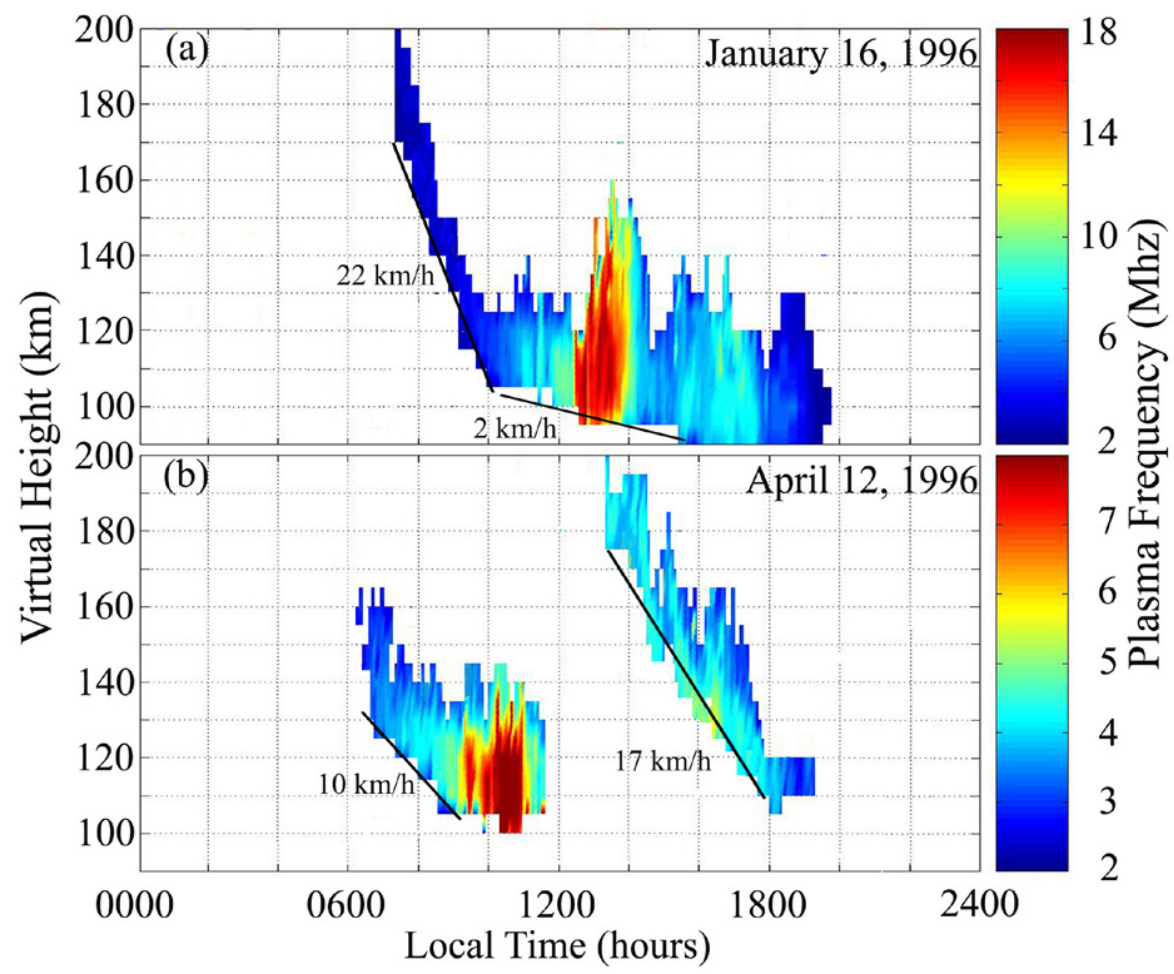

Fig. 5. Height-time-frequency (HTF) plots for 16 January (a) and 12 April (b) 1996, respectively. The horizontal axis of the HTF plot represents the local time, the vertical axis is the virtual height, and the colored level indicates the plasma frequency. This HTF plot is a new approach, which allows a digisonde to determine the variation in plasma density as an intermediate layer descends from high to low altitude.

tide in winter is about twice that in summer. Moreover, production and recombination do not dominate plasma distribution with height in the intermediate region in winter (as shown by Davies, 1990). Therefore, wind shear is primarily responsible for layer formation in winter, and layer formation is expected to be greater during this season.

Early studies (Fujitaka and Tohmatsu, 1973; Mathews and Bekeny, 1979; Tong et al., 1988, Morton et al., 1993; Szuszczewicz et al., 1995) examined the different tidal motions that occur in layer production. These studies indicated that the intermediate layer behavior is controlled mainly by the semi-diurnal and quarter-diurnal tides, but did not clarify the seasonal characteristics of tidal motions. However, this work presents the seasonal variations of the layer in Fig. 3. The significant occurrence probability of the layer (> $50 \%$ ) and the single peak show that the 12-h (semi-diurnal) tide prevails in January-March and November-December. Furthermore, the prevailing 12-h (semi-diurnal) tide during these single-peak months closely resembles the findings of Amayenc (1974). Regarding the double-peak months, although their occurrence probability is below $50 \%$, the 6-h (quarter-diurnal) tide remains more dominant than other tide periods during these months.

In addition to the occurrence probability of the layer, the layer height $\left(h^{\prime}\right.$ Es) behavior also exhibits the tidal characteristics. Harper (1977), MacDougall (1978), Osterman et al. (1994), and Szuszczewicz et al. (1995) reported the de- scent rates associated with semi-diurnal tides to be $8 \mathrm{~km} / \mathrm{h}$, $3.5 \mathrm{~km} / \mathrm{h}, 5.4 \mathrm{~km} / \mathrm{h}$, and $5-8 \mathrm{~km} / \mathrm{h}$, respectively. These previous experimental results closely approximate the initial descent rates, $4-8 \mathrm{~km} / \mathrm{h}$, for single-peak months in this investigation. Furthermore, it is well known that several modes, that is $\mathrm{S}(2,2), \mathrm{S}(2,3), \mathrm{S}(2,4)$, and so on, are included in the semidiurnal tide (such as Williams, 1996). Among these modes, the $S(2,4)$ mode propagates more freely in the lower thermosphere (E-region), because the layers (the semi-diurnal tide) are concentrated in the $100-140 \mathrm{~km}$ region, which is located in the lower ionosphere and in which temperature decreases with height (Williams, 1996). Furthermore, these average descent rates are consistent with the theoretical $\mathrm{S}(2,4)$ mode described by Fujitaka and Tohmatsu (1973) and Mathews and Bekeny (1979). Therefore, it can be treated as the $S(2,4)$ mode with a vertical wavelength of $\sim 50 \mathrm{~km}$ (Bernard and Spizzichino, 1971; Fujitaka and Tohmatsu, 1973; Williams, 1996).

Moreover, the rates $(0.5-1.7 \mathrm{~km} / \mathrm{h})$ unexpectedly decline to below their initial levels when the layer drops below $110 \mathrm{~km}$ during the single-peak months. The mechanism for this phenomenon may be that the downward plasma transport stops near that altitude of the possible dumping level (Chimonas and Axford, 1968). The 100-105 km (virtual height) estimated directly from ionograms in this work closely approaches the dumping level of $100 \mathrm{~km}$ (real height) of the downward semi-diurnal tide identified by Chimonas and $\mathrm{Ax}$ - 
ford (1968) and Mathews and Bekeny (1979).

During the double-peak months, the 6-h period could be categorized to the quarter-diurnal tidal motion. Tong et al. (1988) and Morton et al. (1993) have confirmed that the existence of the 6-h tide exists in their investigations of the intermediate layer and meriodional winds. In these previous studies (Amayenc and Reddy, 1972; Morton et al., 1993), the quarter-diurnal tide was conceived as a high-order component of winds, which would influence the diurnal and semidiurnal components. Notably, the results suggest that the quarter-diurnal tide $(6 \mathrm{~h})$ is a dominant component in AprilJune and August-October. However, the associated occurrence probabilities of below $50 \%$ shows that the quarterdiurnal tides could be an accessory component. Furthermore, the descent rate of the quarter-diurnal tides from Mathews et al. (1993) and Morton et al. (1993), 3.6 km/h, also closely approximates the present analytical result, namely $2-4 \mathrm{~km} / \mathrm{h}$.

Regarding the plasma density of the layer, Osterman et al. (1994, 1995) and Carter and Forbes (1999) demonstrated that molecular metallic ions dominate the compositions of the intermediate layers. In this work, the observed median values for the $f o$ Es of the layers ( $\mathrm{H}$ and $\mathrm{C}$ type) are nearly 4-6 MHz (Fig. 4) at noon, and these values tend to be followed by an overall diurnal behavior that suggests solar control. However, if the layer motion is considered, the increase/decrease of densities is more meaningful. During the single-peak months, the layer descent and associated density increase demonstrate that the descending convergent null could capture a large number of molecular and metallic ions (Osterman et al., 1994, 1995; Carter and Forbes, 1999; Earle et al., 2000). Moreover, the morning descents in the doublepeak months may also share the same cause. On the other hand, layer density does not increase during the afternoon layer descents. The phenomenon of the layer descent and concurrent density decrease resembles the simulation result of Carter and Forbes (1999), who found the evening layer to be less intense than the morning one. Carter and Forbes (1999) further reported that the diffusing zonal wind component in the afternoon would reduce the density (Carter and Forbes, 1999).

For investigating the intermediate layer, the most common observations of the intermediate layers come from ISR and ionosondes (e.g. Mathews et al., 1993; Szuszczewicz et al., 1995; Earle et al., 2000). ISR observations can easily detect the layers at night, when background E-region density is low, as is the signal-to-noise ratio (Earle et al., 2000). The layer data (descent rate, formation time, and final descent altitude) can be obtained from the ISR, except for wind and composition data (Shen et al., 1976; Mathews et al., 1993; Earle et al., 2000). However, during the daytime the layers are less prominent in radar power profiles due to the higher background plasma density in the E-F valley region (Earle et al., 2000). In contrast to the limitation of ISR, the features of layers can be recorded during the daytime by a digisonde (ionosonde). From the changes in altitude and the transformation of Es types, the layers can be clearly identified from the E-F valley ( $\mathrm{H}$ and $\mathrm{C}$ type) to the upper/lower E-region
( $\mathrm{L}$ and $\mathrm{F}$ type). Furthermore, the digisonde can determine the variation in plasma density when an intermediate layer descends from high to low altitude based on the HTF plot.

Furthermore, as is well known, the layers occur both in the daytime and the nighttime. However, in this investigation, the digisonde generally only detects the intermediate layers in the daytime. One reason why the layers were only rarely observed at nighttime is that the plasma frequency (density) is lower than the lowest sounding frequency (1 MHz). Meanwhile, the other reason is that the underlying Es (L/F type) layer may blanket the higher intermediate layer $(\mathrm{H} / \mathrm{C}$ type). The investigation of the intermediate layer suffers from the above limitations; nevertheless, long-term observation demonstrates that the digisonde can permit this kind of study.

\section{Summary and conclusion}

This work examines the monthly variation in layer occurrence probability and tidal motion. The analytical results show that the above phenomenon are more frequent in the winter than in the summer. Moreover, the tidal behavior is evident from the periodicities and descent rates of the layers.

Notably, the semi-diurnal tide dominates in the local spring/winter, while the quarter-diurnal tide prevails in the summer/autumn. This seasonal tidal characteristic is a new result in the equatorial anomaly region. Furthermore, the relationship between the density increase/decrease and layer descent suggests that the molecular and metallic ions could be dominant.

Finally, although the intermediate layers occur at an altitude that is inherently difficult to observe, long-term observation confirms that the digisonde is a useful instrument for exploring the layer characteristics. Wilkinson et al. (1992) have proposed that a conventional ionosonde could provide long-term observations of the intermediate layers. Similarly, the digisonde can offer information on the intermediate layers for comparison during the daytime, like an incoherent radar.

Acknowledgements. The authors would like to thank the National Science Council of the Republic of China, Taiwan for financially supporting this research under Contract Nos. NSC 902111M008062AP3, NSC 902111M008049AP5, and NSC 912111M008017. The authors are also grateful to referees whose valuable comments and suggestions helped to improve the content of this paper.

Topical Editor M. Lester thanks a referee for his help in evaluating this paper.

\section{References}

Amayenc, P. and Reddy, C. A.: Height structure of tidal winds as inferred from incoherent scatter observations, Planet. Space Sci., 20, 1269-1279, 1972.

Amayenc, P.: Tidal oscillations of the meridional neutral wind at midlatitudes, Radio Sci., 9, 281-293, 1974. 
Axford, W. I.: The formation and vertical movement of dense ionized layers in the ionosphere due to neutral wind shears, J. Geophys. Res., 68, 769-779, 1963.

Bernard, R. and Spizzichino, A.: Semi-diurnal wind and temperature oscillations in the E-region observed by the Nançay incoherent scatter experiment, J. Atmos. Terr. Phys, 33, 1345-1352, 1971.

Carter, L. N. and Forbes, J. M.: Global transport and localized layering of metallic ions in the upper atmosphere, Ann., Geophysicae, 17, 190-209, 1999.

Chimonas, G. and Axford, W. I.: Vertical movement of temperate zone sporadic-E layers, J. Geophys. Res., 73, 111-117, 1968.

Davies, K.: Ionospheric Radio, Peter Peregrinus Ltd., London, UK, 1990.

Earle, G. D., Bishop, R. L, Collins, S. C., Gonzalez, S. A., and Sulzer, M. P.: Descending layer variability over Arecibo, J. Geophys. Res., 105, 24 951-24 961, 2000.

Fujitaka, K. and Tohmatsu, T.: A tidal theory of the ionospheric intermediate layer, J. Atmos. Terr. Phys., 35, 425-438, 1973.

Harper, R. M.: Tidal winds in the 100- to $200-\mathrm{km}$ region at Arecibo, J. Geophys. Res., 82, 3243-3250, 1977.

Kelley, M. C.: The Earth's ionosphere: plasma physics and electrodynamics, Academic Press Inc., 1989.

MacDougall, J. W.: Seasonal variation of semidiurnal winds in the dynamo region, Planet. Space Sci., 26, 705-714, 1978.

Mathews, J. D. and Bekeny, F. S.: Upper atmosphere tides and the vertical motion of ionospheric sporadic layers ar Arecibo, J. Geophys. Res., 84, 2743, 1979.

Mathews, J. D., Morton, Y. T., and Zhou, Q.: Observations of ion layer motions during the AIDA campaign, J. Atmos. Solar-Terr. Phys., 55, 447-457, 1993.

Mathews, J. D.: Sporadic-E: current views and recent progress, J. Atmos. Solar-Terr. Phys, 60, 413-435, 1998.

Morton, Y. T., Mathews, J. D., and Zhou, Q.: Further evidence for a 6-h tide above Arecibo, J. Atmos. Solar-Terr. Phys., 55, 459-465, 1993.

Osterman, G. B., Heelis, R. A., and Bailey, G. J.: Modeling the formation of intermediate layers at Arecibo latitudes, J. Geophys. Res., 99, 11357-11365, 1994.

Osterman, G. B., Heelis, R. A., and Bailey, G. J.: Effects of zonal winds and metallic ions in the behavior of intermediate layers, J. Geophys. Res., 100, 7829-7838, 1995.

Reinisch, B. W.: The Digisonde network and databasing, World
Data Center A for Solar-Terrestrial Physical, Report UAG-104, Ionosonde Networks and Stations, 8-15 pp., 1995.

Reinisch, B. W. and Haung, X.: Automatic calculation of electron density profiles from digital ionograms, 3, Processing of bottomside ionograms, Radio Sci., 18, 477-497, 1983.

Reinisch, B. W.: Modern ionosondes, in: Modern Radio Science, (Eds) Kohl, H., Ruester, R., and Schlegel, K., European Geophysical Society, Katlenburg-Lindau, Germany, pp. 440-458, 1996.

Rodger, A. S., Fitzgerald, P. H., and Broom, S. M.: The nocturnal intermediate layer over South Georgia, J. Atmos. Terr. Phys., 43, 1043-1050, 1981.

Shen, J. S., Swartz, W. S., and Farley, D. T.: Ionization layers in the nighttime E-region valley above Arecibo, J. Geophys. Res., 81, 5517-5526, 1976.

Szuszczewicz, E. P., Roble, R. G., Wilkinson, P. J., and Hanbaba, R.: Coupling mechanisms in the lower ionosphericthermospheric system and manifestations in the formation and dynamics of intermediate and descending layers, J. Atmos. SolarTerr. Phys., 57, 1483-1496, 1995.

Titheridge, J. E.: Ionogram analysis with the generalized program POLAN, Report UAG-93, World Data Center A for Solar Terrestrial Physics, 1985.

Tong, Y., Mathews, J. D., and Ying, W.-P.: An upper E-region quarterdiurnal tide at Arecibo, J. Geophys. Res., 93, 10 047-10 051, 1988.

Wakai, N., Ohyama, H., and Koizumi, T.: Manual of ionogram scaling, Radio Research Laboratory, Ministry of Posts and Telecommunications, Japan, 1987.

Whitehead, J. D.: The formation of the sporadic-E layer in the temperate zones, J. Atmos. Terr. Phys., 20, 49-58, 1961.

Whitehead, J. D.: Recent work on mid-latitude and equatorial sporadic-E, J. Atmos. Terr. Phys., 51, 401-424, 1989.

Wilkinson, P. J., Szuszczewicz, E. P., and Roble, R. G.: Measurements and modeling of intermediate, descending, and sporadic layers in the lower ionosphere: results and implications for global-scale ionospheric-thermospheric studies, Geophys. Res. Lett., 19, 95-98, 1992.

Williams, P. J. S.: Tides, atmospheric gravity waves and traveling disturbances in the ionosphere, in: Modern Radio Science, (Eds) Kohl, H., Ruester, R., and Schlegel, K., European Geophysical Society, Katlenburg-Lindau, Germany, pp. 139-180, 1996. 